\title{
PSS-Study: An Exploration of Physiotherapy Student-Perceived Stress and the Related Coping Strategies whilst on Placement
}

\author{
*Jacqueline Bennion ${ }^{a}$, Trystan Symons ${ }^{a}$, Ian Shearman ${ }^{a}$, Charlotte Holloway ${ }^{a}, \&$ \\ Richard Kain ${ }^{a}$ \\ a: Faculty of Health, Social Care and Education, School of Rehabilitation Sciences, Kingston \& \\ St. George's University of London
}

\begin{abstract}
Evidence exploring stress and coping strategies amongst physiotherapy students within clinical practice is lacking. The aim of this study is two-fold: to identify common stressors and coping strategies of BSc and MSc UK physiotherapy students on clinical placement; to explore the relationship between these stressors and coping strategies, and demographics of age, gender and year of study. This cross-sectional study recruited a convenience sample. Participants completed a five-part closed questionnaire. Seventy-seven questionnaires were returned. Frequency counts identified common stressors and coping strategies (\%). Chisquared test analysis identified correlations between variables. Odds ratio analysis highlighted strength of associations. Common stressors: lack of practical skills $(58.4 \%)$; participants' perceived expectations of required knowledge (57.1\%); time demands (55.8\%). Common coping strategies: talking to a friend in the same year of study $(79.2 \%)$; exercise $(68.8 \%)$. Lack of support from university/clinical staff $(p=0.04)$, time demands $(p=0.03)$ were statistically significant stressors in relation to age. Talking to a friend in the year above was a statistically significant coping strategy $(p=0.008)$ for male students. Talking to a clinical educator/ward staff was a statistically significant coping strategy in relation to year of study $(p=0.035)$. Certain stressors were experienced more by second-year BSc and second-year MSc cohorts than the third-year BSc cohort. These findings provide awareness of students who potentially require support in managing stress.
\end{abstract}

Keywords: coping; physiotherapy; stress; students

\section{Introduction}

In the United Kingdom, work-related stress has been linked to illness and absence due to workers' inability to cope with demands placed upon them (Health and Safety Executive [HSE], 2016). In a survey of National Health Service (NHS) staff, 37\% reported feeling unwell due to work-related stress (National Health Service [NHS], 2016). This has now risen to 40.3\% of all NHS staff (NHS, 2019).

*Corresponding Author: Jacqueline Bennion, Therapy Services, the Royal Free NHS Hospital London, Pond Street, London, NW3 2QG, United Kingdom

Email: Jacqueline.Bennion@nhs.net

Journal URL: https://publications.coventry.ac.uk/index.php/pblh

Bennion, J., Symons, T., Shearman, I., Holloway, C., \& Kain, R. (2020). PSS-Study: An exploration of physiotherapy student-perceived stress and the related coping strategies whilst on placement. International Journal of Practice-based Learning in Health and Social Care, 8(2), 68-85. DOI 10.18552/ijpblhsc.v8i2.654.

\section{(c) $(9)$}

BY NC ND (C) 2020 Jacqueline Bennion, Trystan Symons, Ian Shearman, Charlotte Holloway, \& Richard Kain. This Open Access article is distributed under the terms of the Creative Commons Attribution AttributionNon-Commercial No Derivatives 4.0 International License (https://creativecommons.org/licenses/by-nc-nd/4.0/ ), which permits unrestricted non-commercial use, distribution, and reproduction in any medium, provided the original work is properly cited and is unaltered. 
In comparison to other students, those studying healthcare courses reported the highest perceived-stress levels (Jacob et al., 2013). Furthermore, high levels of stress have been reported in physiotherapy students (Walsh et al., 2010). Briner (2004) suggests that when examining stress, no single framework is able to encompass all dimensions of stress. Consequently, it is beneficial to consider multiple theories to provide context to the variable nature of stress.

The transactional model of stress identifies a relationship between the environment and a person's perception of the situation (Bailey \& Clarke, 1989). This framework further defines stress as a combination of stressor and ability to cope effectively, to minimise the influence of the perceived threat, depending on the individual's perception of the stressful stimulus (Bailey \& Clarke 1989). An alternative framework is the Demand-Control model of stress described by Karasek \& Theorell (1990). This model suggests that all perceived work-related stress shares the common themes of low personal control and high external demands. Both models of stress will be referred to throughout to provide a theoretical grounding to the findings of this study.

\section{Background}

A comprehensive search of databases was conducted using the St. George's, University of London (SGUL) library search engine 'Hunter', covering a variety of databases. The authors included studies, published within the previous ten years, concerning medicine, health and care students' stress and/or coping strategies on clinical placement; studies published over ten years ago were excluded. Our search used the keywords; stress, coping, physiotherapy, students.

Our search identified 16,020 results. Forty study titles providing relevant insight into the subject area were progressed to abstract review. The review process excluded articles which were specific to interventions such as mindfulness, or focused on the academic environment or prevention strategies. Twenty-five studies went to full-text examination. Reference lists of the examined articles were scanned to identify further relevant studies. The final eighteen studies included in this study following full-text examination are summarised below.

\section{Stress}

A cross-sectional study in Sweden observed nursing students' perception of stress during clinical practice by evaluating the risk of stressors upon their clinical practice. They found that 43 percent of student nurses reported high stress levels (Blomberg et al., 2014).

Burnard et al. (2007) identified recurring stressors of student nurses, using thematic analysis. Common stressors included lack of perceived knowledge and practical skills, lack of support from clinical staff, and clinical workload.

Timmins et al. (2011) aimed to quantify the frequency of a similar list of stressors experienced by nursing students on clinical placement. The common stressors identified were: attitudes of clinical staff; academic workload; clinical demands; lack of knowledge; and clinical skills.

\section{Coping strategies}

Sandover et al. (2015) carried out a five-year longitudinal study looking at stress, coping strategies and approaches to learning in Australian undergraduate and graduate-entry medical students. The findings suggested that either students adopted a coping strategy or naturally became accustomed to the stress and demands of higher education. Contrary to this finding, Jimenez et al. (2010) found that within a nursing population, students did not become accustomed to stress and demands over time.

Bíró et al. (2016) investigated the relationship between social support and levels of resilience in Hungarian physiotherapy students. The authors identified common coping strategies such as peer and/or family support. Interestingly, students were unaware that their activity choices could be considered as ways of coping. Overall the literature lacks evidence quantifying common coping strategies of healthcare students on clinical placement. 


\section{Demographics}

\section{Age}

There is a lack of information concerning age in relation to stress. However, Bíró et al. (2016) compared mental health of young (under 25 years) and mature physiotherapy students ( 25 years and over). They did not find a significant difference between these groups. Furthermore, the authors focused on the physiotherapy programme in its entirety without specific attention to clinical placements.

\section{Gender}

Female physiotherapy students have been identified as more vulnerable to stress (Bíró et al., 2016). Studies have speculated that this is due to females striving for higher achievement more than males (Blomberg et al., 2014; Jacob et al., 2013; Tucker et al., 2006). Bíró et al. recruited more females than males; however, it could be argued that a female majority is typical of a physiotherapy cohort. Delany \& Bragge (2009) found coping strategies were related to learning and performance. Their study included an equal ratio of gender orientation but their sample was small. Jacob et al., 2013 found no difference when comparing stress levels to gender orientations. Their sample size of 312 had 154 physiotherapy students and included a higher male to female ratio.

\section{Year of study}

A cross-sectional analysis of 626 physiotherapy students in three different countries compared sources of stress across years of study (Jacob et al., 2012). There was no significant difference between physiotherapy students' perceived stress and year of study. Jacob et al. (2012) attribute this lack of significance to the cross-sectional design, whereby a cause-effect relationship could not be established. A longitudinal study would have better suited investigating trends and adaptations of variables across years of study and curricula.

Tucker et al. (2006) found that final-year (4th-year) BSc physiotherapy students in Australia exhibited significantly lower academic stress than students in earlier years. However, this was not identified in final-year ( $3^{\text {rd }}$-year) BSc physiotherapy UK students (Tucker et al., 2006). This may suggest a wider distribution of the workload across four years of study reduces stress levels compared with the same workload across three years of study. No articles were found in the literature search investigating the effect of shortening physiotherapy course length on stress.

\section{Scope for research}

There is a lack of literature exploring levels of stress and coping strategies among physiotherapy students within clinical practice and effective guidance to address the detrimental effects of stress on students' performance Jacob et al., 2013 is therefore not available. The lack of a robust and consistent evidencebase is problematic when attempting to generate a clear and well-defined hypothesis regarding healthcare student stress on clinical placement. Furthermore, the specificity to the UK physiotherapy student population is absent within the available research.

The evidence suggests that the experience and response to stress varies according to the individual and is influenced by different demographics such as age, gender and year of study. Moreover, coping strategies are suggested as a variable worth exploring within a physiotherapy student cohort (Walsh et al., 2010). Accurate identification of stressors and coping strategies and their relationship to students' demographics is required to inform effective guidance for students to manage stress.

\section{Aims}

The aim of this study is two-fold:

(1) To identify common stressors experienced and coping strategies employed by UK Bachelor of Science (BSc) and Master of Science (MSc) physiotherapy students whilst on clinical placement; 
(2) To explore the relationship between the above and the demographics of age, gender and year of study.

\section{Methods}

\section{Design}

This exploratory, cross-sectional study took a convenience sample of BSc and MSc physiotherapy students from St George's, University of London (SGUL). The intention was to provide feedback to the university faculty on the student experience of stressors and coping strategies on clinical placement, providing insight into university support systems.

This study took place between September 2016 and April 2017. The study aimed to recruit a convenience sample in order to gather relevant research data regarding physiotherapy pre-registration clinical placements. Exploratory studies have been shown to generate theories at the earlier stages of research in order to inform later stages of the future research design (Blaikie, 2010).

A cross-sectional study design was deemed appropriate for the aims of this convenience sample as recruitment involved only inclusion and exclusion criteria and self-reported measures of students' exposure to variables, associations of variables and estimated outcomes (Setia, 2016). The study design supports researchers in exploring a research question prior to more comprehensive research investigation (Setia 2016).

\section{Participants/Recruitment}

The inclusion criterion was set as SGUL physiotherapy BSc and MSc pre-registration students who had completed a minimum of one five-week clinical placement. Exclusion criterion was set as any student who had not completed a full clinical placement. Thus, all year one BSc physiotherapy students were excluded due to nil clinical placement experience. The authors identified a maximum of 129 participants eligible for inclusion in this study.

\section{Procedure}

A pilot questionnaire was completed by four third-year BSc students in November 2016 with no feedback or suggestions received implying no need for re-formatting. Data collection commenced in January 2017. The participants were asked to complete a five-part closed questionnaire (see Appendix B) to address the primary aim of identifying stressors and coping strategies on clinical placement, as well as secondary demographical information of the participants. The questions regarding the primary aim were based upon a similar study conducted by Timmins et al., (2011), with a selected list of stressors and coping strategies which were deemed valid following peer-review within a nursing context.

\section{Ethics}

Ethics approval was given by Kingston University Faculty of Health and Social Care Sciences Ethics Committee; Reference: FREC2017-01-014. Following ethical approval a member of the research team provided an introduction and written guidance to potential participants at the beginning of a scheduled lecture (see Appendix A). The guidance explained the purpose and nature of the research study. Adequate time was provided to read the information, contemplate responses and complete the questionnaire voluntarily. Completed questionnaires were handed into a collection box. Consent was implied from all participants who voluntarily completed a questionnaire (see Appendix A). A total of 77 from 129 participants returned completed questionnaires. Dissemination of results was organised for participants once the study was completed. All ethical principles were adhered to throughout the course of the study (Beauchamp \& Childress, 2002).

\section{Analysis}

Statistical analysis was guided by statistical significance testing methods (Greenland et al., 2016). Frequencies (\%) were used to identify common stressors and coping strategies. P-values were used for 
pre-selection of variables, highlighting the findings that would need further methods of analysis to determine association between variables (Cumming, 2013; Simmons et al., 2011; Sperandei, 2014).

IBM Statistics SPSS ${ }^{\circledR} 24$ was used to analyse categorical nominal (e.g. frequencies of stressors and coping strategies) and binary data (e.g.demographical data) collected by the questionnaire. Data was presented and analysed using bar-charts for the nominal data and contingency tables for the binary data due to the multiple number of variables measured.

The Chi-squared test for independence addressed the secondary aim of identifying a correlation between two non-ranked categorical variables (Pallant, 2016). A probability value of $<0.05$ was deemed statistically significant due to the study design and the lack of previous studies identifying a statistically significant interaction, and allowed for pre-selection of important variables (Simmons et al., 2011; Sperandei 2014).

Furthermore, the calculation of odds ratios provided estimation of the strength of the relationship between pre-selected variables. Odds ratios provided further meaning to associated variables by evaluating the strength of the odds of a variable relative to another variable (McHugh, 2009). This method allowed the authors to identify an estimated effect according to each variable. These were presented and analysed using Forrest plots.

\section{Findings}

All 77 students who returned questionnaires completed the entire five-part closed questionnaire. All raw data is available on request.

\section{Primary aim}

The primary aim of this study was to identify common stressors experienced and coping strategies employed by BSc and MSc physiotherapy students in the UK whilst on clinical placement. Frequencies of stressors and coping strategies identified by students are shown in Figure 1 and Figure 2.

The most common stressors identified were: A lack of practical skills (58.4\%); The participants' perceived expectations of knowledge needed (57.1\%); Time demands placed upon participants on placement (55.8\%); End of placement presentation (54.5\%); and Initial ward experiences $(50.6 \%)$.

The most common coping strategies identified were: To talk to a friend in the same year of study (79.2\%); To exercise (68.8\%); and To try sort it out on your own (66.2\%).

\section{Secondary aim}

The secondary aim of this study was to explore the relationship between stressors and coping strategies, and the demographics of age, gender and year of study. Consequently, data from the questionnaire were analysed using Chi-squared test to identify correlations between variables and odds ratio analysis, in order to highlight the strength of associations between variables.

\section{Age}

Of the 77 participants, $35(45.45 \%)$ were $18-24$ years old, 34 (44.16\%) were $25-31$ years old, $3(3.9 \%)$ were $32-38$ years old, and $5(6.49 \%)$ were over 39 years old. Lack of support from university or clinical staff $(p=0.04)$ and Time demands $(p=0.03)$ were identified as significant stressors in relation to age. There was a poor correlation between coping strategies and age. 
Figure 1: Frequencies of stressors experienced by physiotherapy students

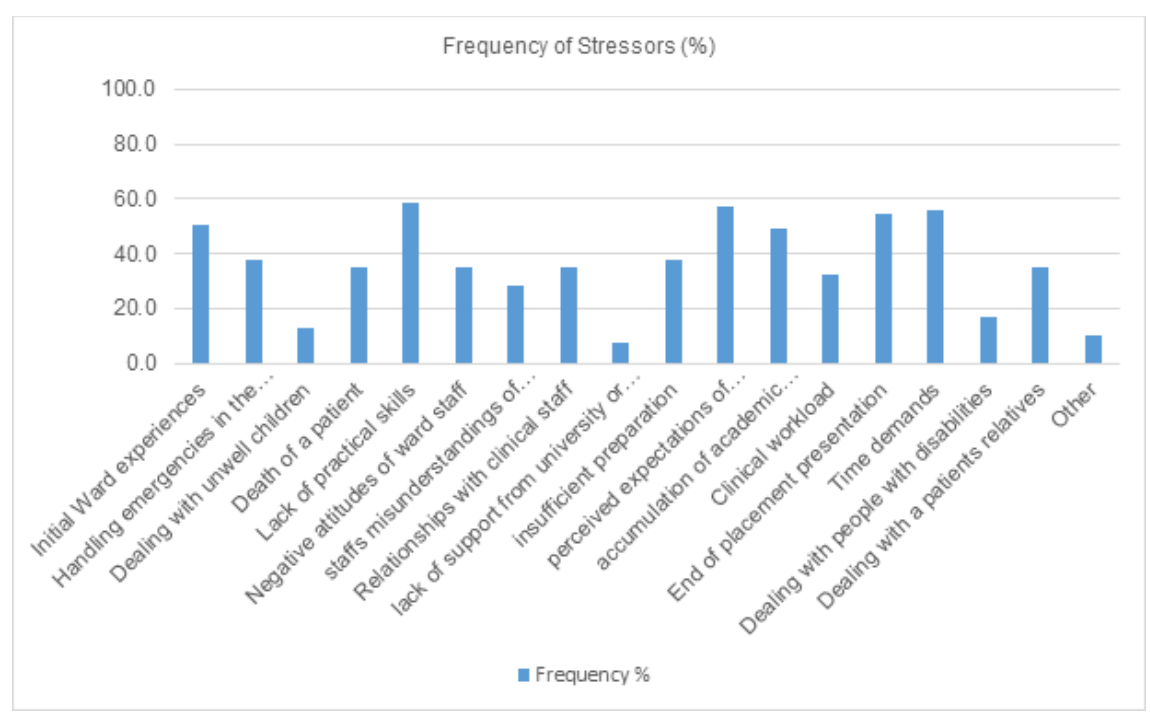

Figure 2: Frequencies of coping strategies used by physiotherapy students

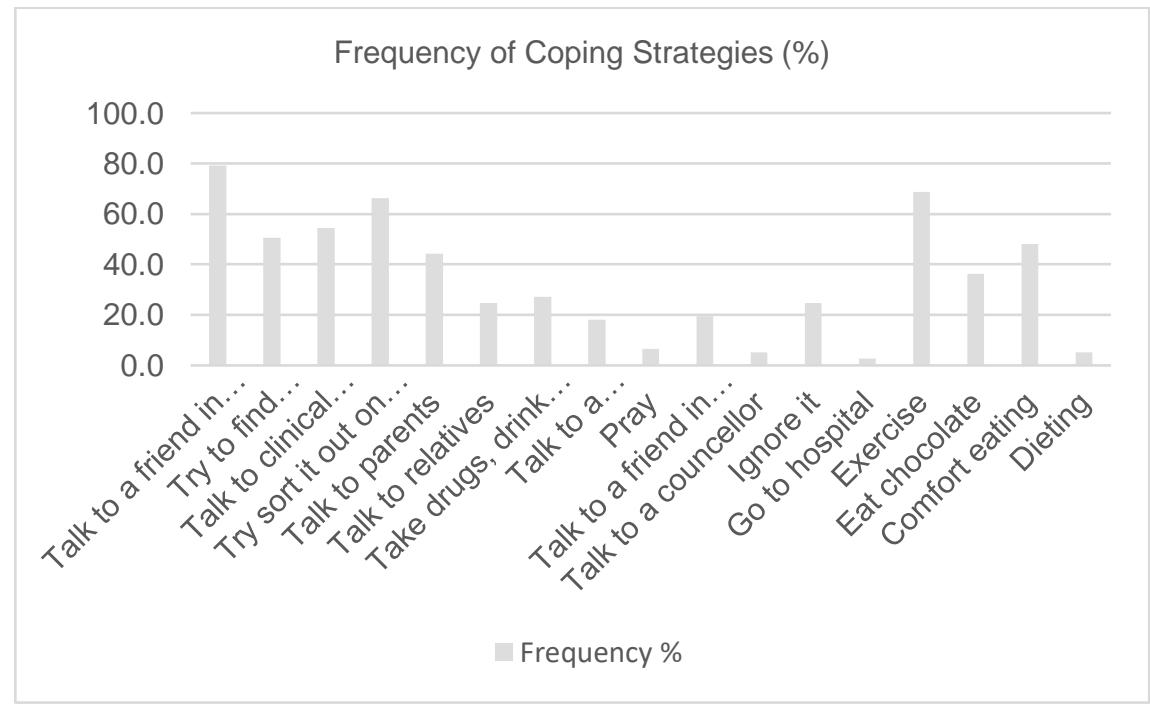

Students aged 32-38 years demonstrated an odds ratio of 0.50 for Lack of support from university or clinical staff as a stressor. This suggests that students in this category were more likely to experience Lack of support from university or clinical staff as a stressor compared to other age categories (see Figure 3 ). 
Figure 3: The following age categories demonstrated odds ratio's for lack of support from university or clinical staff as a stressor: ages 18-24 years: 0; ages 25-31: 0.17; ages 32-38: 0.50 and ages $39+: 0$.

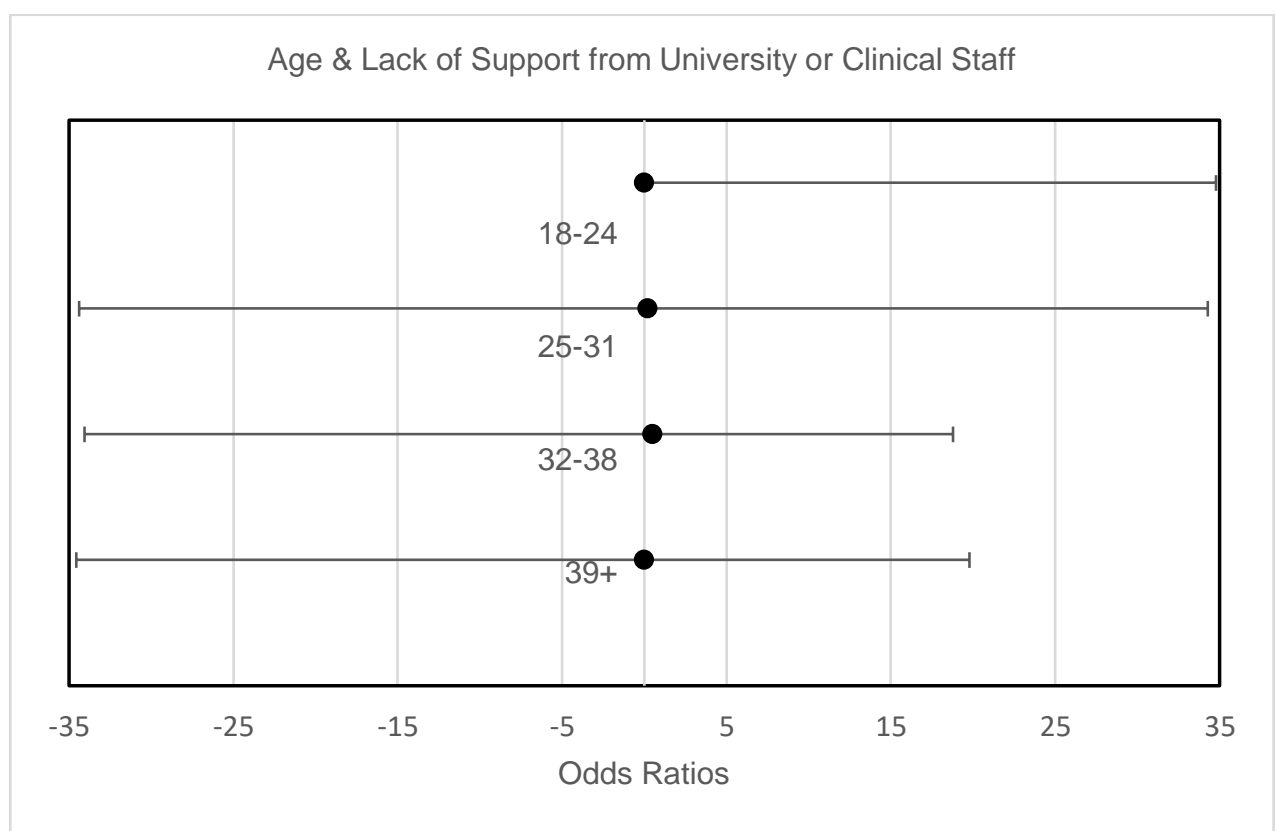

Physiotherapy students aged 18-24 years demonstrated an odds ratio of 0.63 , suggesting that this age category is more predisposed to Time demands as a stressor compared to other age categories (see Figure 4).

Figure 4: The following age categories demonstrated odds raitio's for time demands as a stressor: ages 18-24 years: 0.63; ages 25-31: 0.29; ages 32-38: 0.33 and ages 39+: 0.2 .

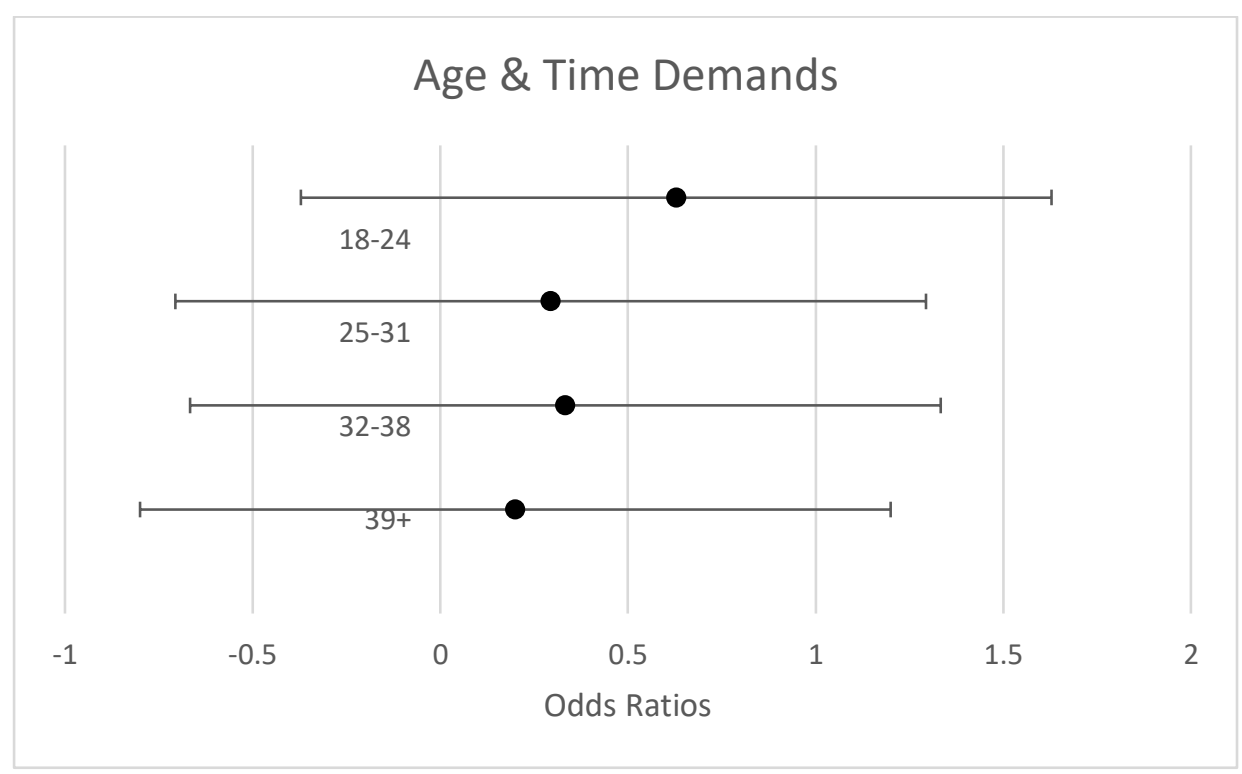

\section{Gender}

Of the 77 participants, $44(57.14 \%)$ of the participants were female. No significant stressors were identified according to gender. However, Talking to a friend in the year above was identified as a statistically significant coping strategy $(p=0.008)$, with more male students $(33.3 \%)$ than female students $(9.1 \%)$ identifying this coping method (see Table 1$)$. 
Table 1: The relationship of gender and Talking to a friend in the year above as a coping strategy

\begin{tabular}{|c|c|c|c|c|c|}
\hline & & & \multicolumn{2}{|c|}{$\begin{array}{l}\text { Talk to a friend in the year(s) } \\
\text { above }\end{array}$} & \multirow[b]{2}{*}{ Total } \\
\hline & & & yes & no & \\
\hline \multirow[t]{4}{*}{ Gender of participant } & \multirow[t]{2}{*}{ Female } & Count & 4 & 40 & 44 \\
\hline & & Expected count & 8.6 & 35.4 & 44.0 \\
\hline & \multirow[t]{2}{*}{ Male } & Count & 11 & 22 & 33 \\
\hline & & Expected count & 6.4 & 26.6 & 33.0 \\
\hline \multicolumn{2}{|l|}{ Pearson Chi-square } & & & & $p=0.008$ \\
\hline
\end{tabular}

Odds ratio analysis was used to explore the strength of association identified by the Chi-squared method. Male physiotherapy students demonstrated an odds ratio of 0.25 and female students 0.01 . This suggests male physiotherapy students were more likely to cope with stress by Talking to a friend in the year above whilst on clinical placement compared to female students. However, the associated relationship between male students and Talking to a friend in the years(s) above was not a strong association.

\section{Year of study}

According to year of study, students (40.26\%) were second-year BSc, 33 (42.86\%) were third-year BSc and $13(16.88 \%)$ were second-year MSc. Initial ward experience was identified as a significant stressor in relation to year of study ( $p=0.005)$, showing that fewer second-year BSc students than expected $(29.0 \%)$ found Initial ward experiences to be stressful. Conversely, within the second year MSc cohort, more students than expected (76.9\%) perceived Initial ward experiences to be stressful. Second-year BSc Physiotherapy students demonstrated an odds ratio of 0.71 , suggesting a stronger associated relationship with Initial ward experiences as a stressor compared to other years of study (see Figure 5).

Handling emergencies in the clinical area was identified as another statistically significant stressor according to year of study ( $p=0.000)$, showing that fewer second-year BSc students than expected (12.9\%) found this to be stressful. Conversely, within the second-year MSc demographic more students than expected (76.9\%) found Handling emergencies in the clinical area to be stressful (see Table 2).

Table 2: The relationship of year of study and Handling emergencies in the clinical area as a stressor

\begin{tabular}{|c|c|c|c|c|c|}
\hline & & & $\begin{array}{l}\text { Hano } \\
\text { clinic }\end{array}$ & ncies in the & \\
\hline & & & yes & no & Total \\
\hline Year of study & Second-year BSc & Count & 4 & 27 & 31 \\
\hline & & Expected count & 11.7 & 19.3 & 31.0 \\
\hline & Third-year BSc & Count & 15 & 18 & 33 \\
\hline & & Expected count & 12.4 & 20.6 & 33.0 \\
\hline & Second-year MSc & Count & 10 & 3 & 13 \\
\hline & & Expected count & 4.9 & 8.1 & 13.0 \\
\hline Pearson Chi-s & are & & & & $p=0.000$ \\
\hline
\end{tabular}

Second-year BSc Physiotherapy students demonstrated an odds ratio of 0.87, suggesting a stronger associated relationship with Handling emergencies in the clinical area as a stressor compared to other years of study. Third-year BSc Physiotherapy students demonstrated an odds ratio of 0.55. 
Figure 5: The following years of study demonstrated odds raitio's Initial ward experiences as a stressor: the second-year BSc cohort, 0.71; third-year BSc, 0.39; and second-year MSc, 0.23 .

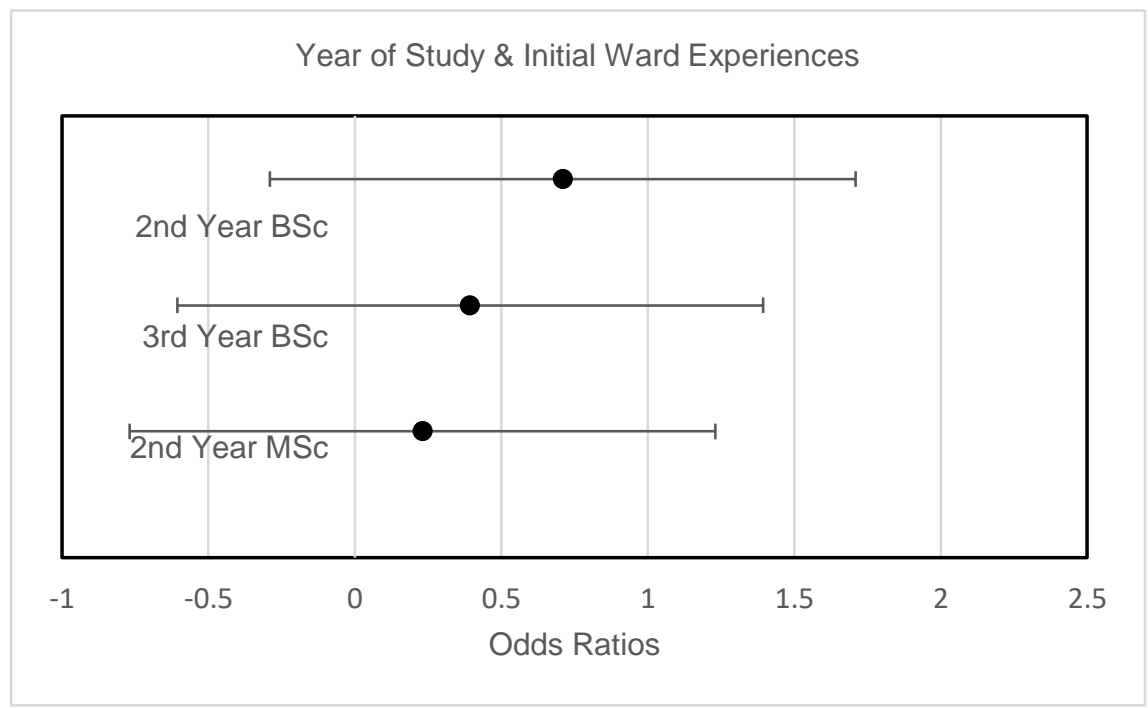

Figure 6: The following years of study demonstrated odds raitio's for Negative attitudes of ward staff as a stressor: the second-year BSc cohort, 0.84; third-year BSc, 0.42; and second-year MSc, 0.77 .

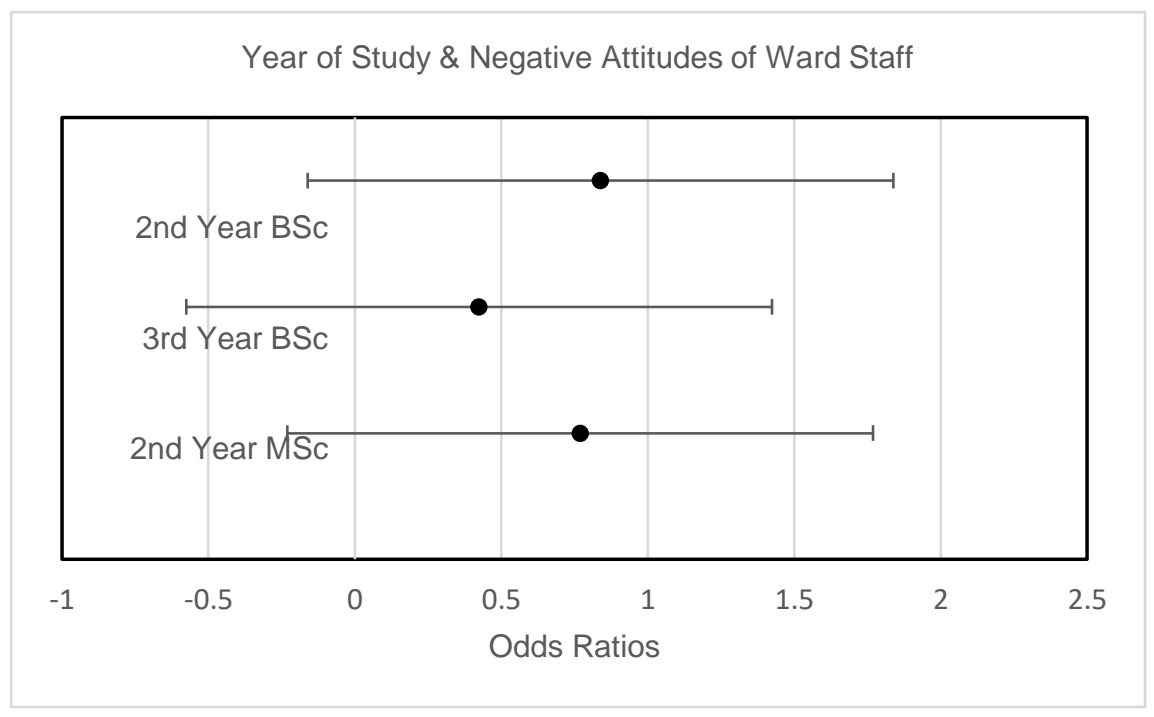

Furthermore, Death of a patient $(p=0.05)$, Lack of support from university or clinical staff $(p=0.01)$ and Negative attitudes of ward staff $(p=0.001)$, were identified as statistically significant stressors according to year of study. Second-year BSc Physiotherapy students demonstrated an odds ratio of 0.81 suggesting a stronger associated relationship with the Death of a patient as a stressor compared with other years of study. Both second-year BSc Physiotherapy students and second-year MSc students demonstrated an odds ratio of 1.0 suggesting that both academic cohorts were equal in strength of associated relationship with Lack of support from university and clinical staff as a stressor. Third-year BSc Physiotherapy students demonstrated an odds ratio of 0.82 , which is comparable to second-year BSc and MSc students. 
Fewer second-year BSc students than expected (16.1\%) found Negative attitudes of ward staff to be stressful. Conversely, within the third-year BSc cohort, more students than expected (57.6\%) perceived Negative attitudes of ward staff to be stressful. Second-year BSc Physiotherapy students demonstrated an odds ratio of 0.84 , suggesting an associated relationship with Negative attitudes of ward staff as a stressor compared to other years of study. Second-year MSc Physiotherapy students demonstrated an odds ratio of 0.77; thus, a comparable association to the second-year BSc year of study (see Figure 6).

Talking to a clinical educator or ward staff was a statistically significant coping strategy identified in relation to the year of study $(p=0.035)$ (see Table 3).

Table 3: The relationship of year of study and Talking to a clinical educator or hospital staff as a coping strategy.

\begin{tabular}{|c|c|c|c|c|c|}
\hline & & & $\begin{array}{l}\text { Talk } \\
\text { hosp }\end{array}$ & ucator or & \\
\hline & & & yes & no & Total \\
\hline Year of study & Second-year BSc & Count & 13 & 18 & 31 \\
\hline & & Expected count & 16.9 & 14.1 & 31.0 \\
\hline & Third-year BSc & Count & 18 & 15 & 33 \\
\hline & & Expected count & 18.0 & 15.0 & 33.0 \\
\hline & Second-year MSc & Count & 11 & 2 & 13 \\
\hline & & Expected count & 7.1 & 5.9 & 13.0 \\
\hline Pearson Chi-s & are & & & & $p=.035$ \\
\hline
\end{tabular}

The second-year MSc cohort demonstrated a large odds ratio of more than one (30.25) which suggests either a very strong association between their year of study and coping by Talking to the clinical educator or hospital staff, or, despite checking for errors, an error may have existed.

\section{Discussion}

The primary aim of this study included identifying common stressors among a convenience sample of UK BSc and MSc physiotherapy students. Our findings are comparable to the findings of Timmins et al. (2011), who found that the most common stressors experienced by nursing students on clinical placement were lack of perceived knowledge and practical skills.

Lack of practical skills and Perceived expectation of knowledge required were found to be the most frequently perceived stressors in our study (58.4\% and $57.1 \%$ respectively). These findings support previous research including that by Chipchase et al. (2012), who explored clinical educators' priorities surrounding student preparedness for clinical placement. Their thematic analysis identified knowledge and practical skills as two of six essential criteria of what constitutes a 'prepared student'. Therefore, clinical educators' apparent prioritisation of these factors may contribute to the high frequencies of Lack of practical skills and Perceived expectation of knowledge needed, identified as students' stressors in this study. Furthermore, Delany \& Bragge (2009) recommended decreasing the student-educator discrepancy in expectation of knowledge and skills, to potentially address the high levels of student perceived stress. Burnard et al. (2007) also found a perceived lack of knọwledge to be a common stressor amongst nursing students, identifying this to be consistent across healthcare students in general.

Time demands and End of placement presentations were identified as additional common stressors in this study (55.8\% and 54.5\% respectively). Although not explained in previous research, the authors of this study speculate that presenting to senior or qualified personnel is more stressful than presenting to peers. 
This study found Initial ward experiences were common reported stressors (50.6\%). Although not specific to Initial ward experiences, Blomberg et al. (2014) identified acute hospital ward experiences as triggering a heightened student stress response due to lack of familiarity.

Another primary aim of this study was to investigate the frequency of common coping strategies used by the sample of students in the clinical environment. Research by Timmins et al. (2011) and Bíró et al. (2016) revealed findings consistent with this study, ranking the broad category of social and peer support as a preferred coping method. This study identifies peer support as a coping strategy, as our data ranked Talking to a friend in the same year of study as the most commonly utilised coping method. Sevenhuysen et al. (2015) found that peer-assisted learning can have the beneficial effects of creating a safe learning environment, increasing feedback capability, and reducing student anxiety. This potentially provides insight into the high frequency use of the peer-support strategy in this study.

Bíró et al. (2016) reported that physiotherapy students often took an individual approach in relation to coping mechanisms. Amongst these individual coping methods, physical activity was found to be commonly utilised, comparable to the findings of this study. Other related research failed to comment on the specific use of exercise as a coping mechanism. However, the authors speculate that exercise may be a more favourable coping method within a physiotherapy population due to the nature of the profession.

The secondary aim of this study was to explore the relationship between common stressors and coping strategies, and the demographics of age, gender and year of study. The results of this study suggest that there is an association between students aged between 32 and 38 and Lack of support from university or clinical staff as a stressor. However, the use of odds ratios indicated this is a weak association. The authors suggest that this could be due to stress and coping strategies being an individual experience and not necessarily related to age, as suggested by Bíró et al. (2016).

This study found no significant correlation between gender and common stressors, supporting the results of earlier work by Bíró et al. (2016), Blomberg et al. (2014), and (Jacob et al., 2013) who were in agreement that females were more vulnerable to stress within a physiotherapy student population. Despite an absence of significant findings between gender and coping strategies in this study, a significant relationship was identified between male students and the coping strategy of Talking to a friend in the year above $(p=0.008)$. However, this relationship showed a weak association as highlighted by the use of odds ratios. Further investigation might provide insight into whether this is an anomaly within the category.

Results showed that there were significant findings between year of study and stressors. The common stressors identified were: Handling emergencies in the clinical area $(p=0.000)$; Negative attitudes of ward staff ( $p=0.001)$; and Initial ward experiences $(p=0.005)$.

The second-year MSc cohort found Negative attitudes of ward staff to be a stressor. However, there was a discrepancy in the results between the BSc cohort with fewer second-year students and more third-year students finding Negative attitudes of ward staff to be a stressor. Odds ratio analysis demonstrated an association between the stressor of negative staff attitudes and the second-year BSc cohort and third-year MSc cohort. There is no previous research that the authors are aware of to support these findings.

There were more MSc physiotherapy students than expected who found Initial ward experiences and Handling emergencies in the clinical area stressful. Applying the transactional model of stress as a lens on our results could suggest that MSc students are more vulnerable to stress due to the compacted course content and demands compared to third-year BSc students. This is supported by Sandover et al. (2015) who found that Australian students studying a four-year course perceived reduced stress levels as compared to UK students studying a three-year course. When considering the Demand-Control model of stress (Karasek \& Theorell, 1990), the second-year BSc students were assumed to have lower personal control which should have resulted in increased stress. However, despite a comparable association between stressors, the second-year BSc students were repeatedly shown to have less stressors, which is not in keeping with the model.

The results of this study suggested an association between the third-year BSc cohort and Talking to a clinical educator or hospital staff as a coping strategy. This is in contrast to Bíró et al. (2016) who reported that, as physiotherapy students progress through a course, their coping strategy has a tendency to 
change to an individual method. However, Bíró et al. (2016) did not specifically focus on clinical placement, which could account for the different findings. There were no further significant relationships between year of study and coping strategies identified in our results.

This study found certain stressors were experienced more by the second-year BSc and second-year MSc cohorts than the third-year BSc cohort. These findings begin to provide an awareness of physiotherapy students who potentially require further support in managing stress whilst on clinical placement. The study has provided insight into frequencies of stressors and coping strategies as well as relationships between these and students' demographics of age, gender and year of study. While some patterns are evident in the data, no formal conclusions can be drawn due to the lack of consistency and compatibility with this study and the current evidence. Further investigation is needed to determine the robustness of our results. This cross-sectional study is understood to be the first study of its kind within a physiotherapy setting. The authors believe this study provides foundational data to build upon in future research.

\section{Limitations}

This cross-sectional study took a convenience sample of BSc and MSc physiotherapy students from SGUL, and therefore findings may not be applicable to other settings. The intention of this study was to provide feedback to the university faculty on the student experience of stressors and coping strategies on clinical placement, leading to insight into how the university can support students through this challenging time. The study was not extended across additional UK universities and therefore this may have limited the findings of our study.

Sample size was lower than expected, with only 77 out of a potential 129 students participating. However, setting confidence intervals at $p<0.05$ has maximised the likelihood of significant findings and allowed for meaningful association between variables using odds ratio analysis.

Nederhof (1985) demonstrates the common occurrence of social desirability bias within experimental and survey research. Although attempts were made to limit this bias by adopting Nederhof's (1985) methods of bias reduction (e.g. self-administration of the questionnaire and forced-choice items format), the authors recognise a degree of inevitability with regards to this bias with an undetermined effect on the study's internal validity.

The authors appreciate that the second-year BSc students may not have been exposed to stressors specific to some clinical environments. This variation could be considered a potentially confounding factor in the reported findings. This may explain the large odds ratio for the second-year MSc cohort which was more than 1 .

\section{Conclusion}

To the best of the authors' knowledge this is the only study specifically looking at the stressors experienced and the coping strategies utilised by UK physiotherapy students on clinical placement. This study found certain stressors were experienced more by the pre-registration MSc cohort. These findings highlight cohorts of students who potentially require further support in managing stress. Understanding stress whilst on clinical placement could equip educators and university staff to empower students to be resilient and productive life-long learners. The Demand-Control model of stress (Karasek \& Theorell, 1990) suggests that all perceived work-related stress shares the common themes of low personal control and high external demands. It is a priority to empower current healthcare students to engage in quality practice and life-long learning, thus, potentially reducing the $40.3 \%$ of all NHS staff (NHS, 2019) who reported feeling unwell due to work-related stress, whilst improving quality of practice and staff productivity. However, providing further advice on feasible solutions to alleviate this stress is beyond the scope of this research.

On the basis of the findings of this exploratory study, a suggestion for future research may include a longitudinal mixed-methods design study, to add rich descriptive narrative and give further specificity regarding possible university and clinical educators' support strategies. Completing a longitudinal study with a mixed-methods design over the course of an academic year will minimise the discussed bias of 
variability in clinical exposure and observe the consistency of findings over time whilst providing meaning behind data collected.

\section{Acknowledgements}

The authors would like to thank all the physiotherapy students of St. George's, University of London who participated in this study and those who encouraged and supported us to submit for publishing including those at the National Association of Educators in Practice (NAEP) conference in 2018.

\section{Ethical approval}

Ethics approval was given by Kingston University Faculty of Health and Social Care Sciences Ethics Committee; Reference: FREC2017-01-014.

\section{ORCID}

Jacqueline Bennion

Trystan Symons

Ian Shearman

Charlotte Holloway

Richard Kain https://orcid.org/0000-0001-6047-9277

https://orcid.org/0000-0003-2513-7057

https://orcid.org/0000-0002-0547-5924

https://orcid.org/0000-0002-2232-0596

https://orcid.org/0000-0001-8267-0259

\section{References}

Bailey, R., \& Clarke, M., (1989). Stress and coping in nursing. Chapman Hall.

Beauchamp, T., \& Childress, J. (2002). Principles of biomedical ethics (5th ed.). Oxford University Press.

Bíró, É., Veres-Balajti, I., \& Kósa, K., 2016. Social support contributes to resilience among physiotherapy students: A cross sectional survey and focus group study. Physiotherapy, 102(2), 189-195. https://doi.org/10.1016/j.physio.2015.05.002

Blaikie, N. (2010). Designing Social Research (2nd ed.). Polity Press.

Bland, J. M., \& Altman, D. G. (2010). Statistical methods for assessing agreement between two methods of clinical measurement. International Journal of Nursing Studies, 47(8), 931-936. https://doi.org/10.1016/j.ijnurstu.2009.10.001

Blomberg, K., Bisholt, B., Kullén Engström, A., Ohlsson, U., Sundler Johansson, A., \& Gustafsson, M. (2014). Swedish nursing students' experience of stress during clinical practice in relation to clinical setting characteristics and the organisation of the clinical education. Journal of Clinical Nursing, 23(15-16), 2264-2271. https://doi.org/10.1111/jocn.12506

Briner, R. (2004). Psychosocial aspects of work and well-being. In Beyond understanding? Chief Medical Officer's Report 2004 (pp. 4-16). Unum-Provident.

Burnard, P., Haji Abd Rahim, H. T. B., Hayes, D., \& Edwards, D. (2007). A descriptive study of Bruneian student nurses' perceptions of stress. Nurse Education Today, 27(7), 808-818. https://doi.org/10.1016/j.nedt.2006.11.002

Chipchase, L. S., Buttrum, P. J., Dunwoodie, R., Hill, A. E., Mandrusiak, A., \& Moran, M. (2012). Characteristics of student preparedness for clinical learning: Clinical educator perspectives using the Delphi approach. BMC Medical Education, 12 (1), 112. https://doi.org/10.1186/1472-6920$12-112$

Cumming, G. (2013). The new statistics: Why and how. Psychological Science, 25(1), 7-29. https://doi.org/10.1177/0956797613504966

Delany, C., \& Bragge, P. (2009). A study of physiotherapy students' and clinical educators' perceptions of learning and teaching. Medical Teacher, 31(9), e402-e411. https://doi.org/10.1080/01421590902832970 
Greenland, S., Senn, S. J., Rothman, K. J., Carlin, J. B., Poole, C., Goodman, S. N., \& Altman, D. G. (2016). Statistical tests, $P$ values, confidence intervals, and power: A guide to misinterpretations. European Journal of Epidemiology, 31(4), 337-350. https://doi.org/10.1007/s10654-016-0149-3

HSE (Health and Safety Executive). (2016). Stress at work - HSE. Retrieved 1 April 2017, from http://www.hse.gov.uk/stress/

Jacob, T., Gummesson, C., Nordmark, E., El-Ansary, D., Remedios, L., \& Webb, G. (2012). Perceived stress and sources of stress among physiotherapy students from 3 countries. Journal of Physical Therapy Education, 26(3), 57-65. https://doi.org/10.1097/00001416-201207000-00008

Jacob, T., Itzchak, E. B., \& Raz, O. (2013). Stress among healthcare students - A cross disciplinary perspective. Physiotherapy Theory and Practice, 29(5), 401-412. https://doi.org/10.3109/09593985.2012.734011

Jimenez, C., Navia-Osorio, P. M., \& Diaz, C. V. (2010). Stress and health in novice and experienced nursing students. Journal of Advanced Nursing, 66(2), 442-455. https://doi.org/10.1111/j.13652648.2009.05183.x

Karasek, R., \& Theorell, T. (1990). Healthy work: Stress, productivity, and the reconstruction of working life. Basic Books.

McHugh, M. L. (2009). The odds ratio: Calculation, usage, and interpretation. Biochemia Medica, 19(2), 120-126. https://doi.org/10.11613/bm.2009.011

National Health Service. (2016). Staff Survey 2015 - Detailed spreadsheets. Retrieved 1 January 2017, from https://www.uhb.nhs.uk/Downloads/pdf/NationalNhsStaffSurveyResults2015.pdf

National Health Service. (2019). NHS Staff Survey 2019 National results briefing. Nhsstaffsurveys.com. Retrieved 11 December 2020, from https://www.nhsstaffsurveys.com/Caches/Files/ST19_National\%20briefing_FINAL\%20V2.pdf

Nederhof, A. J. (1985). Methods of coping with social desirability bias: A review. European Journal of Social Psychology, 15(3), 263-280. https://doi.org/10.1002/ejsp.2420150303

Pallant, J. (2016). SPSS survival manual: A step by step guide to data analysis using SPSS for Window (6th ed.). Open University Press.

Sandover, S., Jonas-Dwyer, D., \& Marr, T. (2015). Graduate entry and undergraduate medical students' study approaches, stress levels and ways of coping: A five year longitudinal study. $B M C$ Medical Education, 15(1), 5. https://doi.org/10.1186/s12909-015-0284-7

Setia, M. S. (2016). Methodology series module 3: Cross-sectional studies. Indian Journal of Dermatology, 61(3), 261-264. https://doi.org/10.4103/0019-5154.182410

Sevenhuysen, S., Farlie, M. K., Keating, J. L., Haines, T. P., \& Molloy, E. (2015). Physiotherapy students and clinical educators perceive several ways in which incorporating peer-assisted learning could improve clinical placements: A qualitative study. Journal of Physiotherapy, 61(2), 87-92. doi: https://doi.org/10.1016/j.jphys.2015.02.015

Simmons, J. P., Nelson, L. D., \& Simonsohn, U. (2011). False-positive psychology: Undisclosed flexibility in data collection and analysis allows presenting anything as significant. Psychological Science, 22(11), 1359-1366. https://doi.org/10.1177/0956797611417632

Sperandei, S. (2014). Understanding logistic regression analysis. Biochemia Medica, 24(1), 12-18. https://doi.org/10.11613/BM.2014.003

Timmins, F., Corroon, A. M., Byrne, G., \& Mooney, B.(2011). The challenge of contemporary nurse education programmes. Perceived stressors of nursing students: Mental health and related lifestyle issues. Journal of Psychiatric and Mental Health Nursing, 18(9), 758-766. https://doi.org/10.1111/j.1365-2850.2011.01780.x

Tucker, B., Jones, S., Mandy, A., \& Gupta, R. (2006). Physiotherapy students' sources of stress, perceived course difficulty, and paid employment: Comparison between Western Australia and United Kingdom. Physiotherapy Theory and Practice, 22(6), 317-328. https://doi.org/10.1080/09593980601059550

Walsh, J. M., Feeney, C., Hussey, J., \& Donnellan, C. (2010). Sources of stress and psychological morbidity among undergraduate physiotherapy students. Physiotherapy, 96(3), 206-212. https://doi.org/10.1016/j.physio.2010.01.005 


\section{Appendices}

\section{Appendix A}

\section{Participant Information Sheet}

\section{Title of study}

An exploration of physiotherapy student-perceived stress and the related coping strategies

whilst on placement.

\section{Research Aims}

- To identify common stressors experienced and coping strategies employed by physiotherapy students whilst on clinical placements.

- To explore the relationship between the above and the demographics of age, gender and year of study.

\section{Why have I been chosen?}

You have been chosen to take part in this study because you are a physiotherapy student studying at St. George's, University of London and have undertaken at least one clinical placement.

\section{Participant expectation}

You will be asked to complete a short questionnaire which will take you no longer than 10 minutes to complete. The questionnaire will relate to stressful situations you encountered on clinical placements and the methods in which you coped with stress.

\section{Do I have to take part?}

No, whether or not you choose to take part in this study is entirely your decision and will not affect your standing as a student at this university. If after careful consideration you decide to take part in this study by completing the questionnaire on page three and placing it in the collection box, you are giving your implied consent. You can however, choose to withdraw from the study at any time by not completing the questionnaire or by not placing your questionnaire in the collection box.

\section{What will happen to me if I take part?}

After completing the questionnaire there is no requirement for any further involvement.

If you are interested in the results of the study please contact one of the research team using the provided contact information.

\section{What are the possible benefits of taking part?}

You, along with the other participants in this research study, have an opportunity to further the understanding in this field by contributing to a study which has not been done before.

\section{What are the possible disadvantages and risks of taking part?}

It is possible that the process of completing this questionnaire may cause you some distress due to provoking potential unpleasant memories. If this is the case, feel free to stop at any time and if you feel you would like to talk to someone about these feelings please refer to the contact information below for supportive services.

St. George's University counselling services - Tel: ... 
E-mail: ...

\section{Will my taking part in this study be kept confidential?}

Yes, we do not require any personal information from you. As these questionnaires are intended to be anonymised please do not provide any information that may identify you. Although we ask for some demographical information from you the categories have designed to minimise the risk of identification.

\section{What will happen to the results of the research study?}

The results of this study will be collected together and reported on. As mentioned above you will not be identified in this report. Although this is study is intended for an undergraduate research project there is a possibility that this report could be published in a healthcare journal.

\section{Who is organising and funding the research?}

This research has been organised by the research team listed below. There is no internal or external funding to be declared.

\section{Who has reviewed this study?}

This research study has been reviewed by University Research Committee at St. George's, University of London.

\section{Contact for further information?}

If you have any further questions regarding the nature of this study you can contact:

[researcher and councellor contact details] 


\section{Appendix B \\ Participant Questionnaire}

1. Age -- please tick one of the following

$18-24$

$25-31$

$32-38$

$39+$

2. Gender - please tick one of the following

Female

Male

Transgender

3. Year of study - please tick one of the following

2nd-year BSc

3rd-year BSc

2nd-year MSc

4. Below is a list of common stressors that you may have encountered whilst on clinical placement. Please tick any of the following that you have experienced as a stressful situation.

Initial ward experiences

Handling emergencies in the clinical area

Dealing with unwell children

Death of a patient

Lack of practical skills

Negative attitudes of ward staff

Staff's misunderstanding of students' supernumerary status

Relationships with clinical staff

Lack of support from university and clinical staff

Insufficient preparation

Perceived expectations of knowledge needed

Accumulation of academic workload during placement

Clinical workload

End of placement presentation

Time demands

Dealing with people with disabilities

Dealing with patients relatives

Other 
5. Below is a list of common strategies that are used to cope with stressful situations. Please tick any of the following that you used to cope with the stressful experience(s) you indicated in question 4.

Talk to a friend in the same year of study

Try to find information about the situation

Talk to clinical educator / hospital staff

Try and sort it out on your own

Talk to parents

Talk to relatives

Take drugs

Drink

Get drunk

Talk to lecturer/link tutor

Talk to GP

Talk to chaplain/Religious leader

Pray/meditate

Talk to a friend in the year (s) above

Talk to councellor

Ignore it

Go to hospital

Exercise

Eat chocolate

Comfort eating

Dieting 